\title{
Peritoneal carcinomatosis from ovarian cancer: chemosensitivity test and tissue markers as predictors of response to chemotherapy
}

\author{
Chiara Arienti', Anna Tesei ${ }^{1}$, Giorgio Maria Verdecchia ${ }^{2}$, Massimo Framarini ${ }^{2}$, Salvatore Virzi ${ }^{3}$, Antonio Grassi ${ }^{3}$, \\ Emanuela Scarpi ${ }^{1}$, Livia Turci ${ }^{1}$, Rosella Silvestrini ${ }^{1}$, Dino Amadori ${ }^{1}$ and Wainer Zoli ${ }^{*}$
}

\begin{abstract}
Background: Platinum-based regimens are the treatments of choice in ovarian cancer, which remains the leading cause of death from gynecological malignancies in the Western world. The aim of the present study was to compare the advantages and limits of a conventional chemosensitivity test with those of new biomolecular markers in predicting response to platinum regimens in a series of patients with peritoneal carcinomatosis from ovarian cancer.
\end{abstract}

Methods: Fresh surgical biopsy specimens were obtained from 30 patients with primary or recurrent peritoneal carcinomatosis from ovarian cancer. ERCC1, GSTP1, MGMT, XPD, and BRCA1 gene expression levels were determined by Real-Time RT-PCR. An in vitro chemosensitivity test was used to define a sensitivity or resistance profile to the drugs used to treat each patient.

Results: MGMT and XPD expression was directly and significantly related to resistance to platinum-containing treatment $(p=0.036$ and $p=0.043$, respectively). Significant predictivity in terms of sensitivity and resistance was observed for MGMT expression ( $75.0 \%$ and $72.5 \%$, respectively; $\mathrm{p}=0.03$ ), while high predictivity of resistance (90.9\%) but very low predictivity of sensitivity (37.5\%) $(p=0.06)$ were observed for XPD. The best overall and significant predictivity was observed for chemosensitivity test results $(85.7 \%$ sensitivity and $91.3 \%$ resistance; $p=$ 0.0003).

Conclusions: The in vitro assay showed a consistency with results observed in vivo in 27 out of the 30 patients analyzed. Sensitivity and resistance profiles of different drugs used in vivo would therefore seem to be better defined by the in vitro chemosensitivity test than by expression levels of markers.

\section{Background}

The selection of a chemotherapy regimen for individual tumors is normally based on histology, clinical characteristics of the patient and retrospective evidence from randomized clinical trials. However, patients with the same tumor histotype, especially in solid malignancies, often respond differently to the same chemotherapy regimen due to intertumor heterogeneity. Despite knowledge of such heterogeneity, chemotherapy is still largely empirically planned, and the acquisition of

\footnotetext{
* Correspondence: w.zoli@irst.emr.it

'Biosciences Laboratory, Istituto Scientifico Romagnolo per lo Studio e la Cura dei Tumori (I.R.S.T.), Meldola, Italy

Full list of author information is available at the end of the article
}

information for tailored therapy has consequently become a priority in the management of cancer patients today.

Such a goal was intensively pursued in the 1980 s by American and European research groups who developed a number of chemosensitivity tests using fresh material from human tumors and based on the determination of cell proliferation (clonogenic potential and $3 \mathrm{H}-$ thymidine incorporation) or total cell evaluation (dye exclusion, sulphorhodamine blue, MTT assay and ATP bioluminescence) [1-6]. The results obtained from the different tests were compared and their clinical relevance verified in a number of translational clinical studies [5,7-10]. However, various methodological 
problems and technical skills required have limited the widespread clinical use of in vitro experimental results. With the advent of molecular biology at the end of the nineties, attention moved towards the search for molecular and genetic markers involved in proliferation and DNA repair processes that might be predictive of response to both conventional cytotoxic and target therapy drugs [11].

Platinum or platinum-based regimens are the treatment of choice in ovarian cancers, which remains the leading cause of death from gynecological malignancies in the Western world [12]. The absence of specific symptoms in the early stages of the disease results in the majority of patients being diagnosed when the disease is advanced [13]. Currently, standard primary therapy for advanced disease involves surgical debulking followed by platinum/taxane-based chemotherapy [14]. However, despite initially high response rates, a large proportion of patients often experience peritoneal relapse. Recurrent disease is treated with the same regimen used for first-line chemotherapy (i.e., re-induction therapy) or with second- or third-line regimens.

Resistance to platinum alone or in combination is multifactorial. Several studies have attempted to clarify the mechanisms behind resistance to platinum-based chemotherapy, whether intrinsic, as observed in colorectal, prostate, breast or lung cancer, or acquired during treatment. At present, numerous molecular pathways are known to be involved in drug resistance, especially that of platinum compounds. Among such pathways, increased DNA repair and enhanced drug efflux and/or inactivation play an important role in platinum resistance and may also be instrumental in predicting patient prognosis in a clinical setting $[11,15,16]$.

One of the mechanisms involved in DNA repair is the nucleotide excision repair (NER) system, which recognizes helix-distorting base lesions and is presumed to be one of the determinants of platinum resistance [15]. The role of excision repair cross-complementation group1 (ERCC1) in the NER pathway is to incise the DNA strand on the 5' site relative to platinated DNA damage, and its overexpression has been associated with clinical resistance to cisplatin $[17,18]$. Xeroderma pigmentosum group $\mathrm{D}(X P D)$ is another of the several genes involved in the NER pathway. In particular, $X P D$ opens an approximately 30 -baseline DNA segment around the damage. It has also been reported that underexpression of $X P D$ in cells with transcription coupled-NERdeficiency results in hypersensitivity to cisplatin [19].

DNA adducts at the O6-position of guanine can be repaired by NER but also by O6 methylguanine-DNA methyltransferase $(M G M T)$, which is described as a competitor of the NER mechanisms of repair [20]. Preliminary studies have shown that MGMT-deficient cells are unable to repair damage and are more sensitive to the effect induced by alkylating agents than MGMTproficient cells [21].

Breast cancer gene 1 (BRCA1), an essential component of multiple DNA damage repair pathways, is considered to be a differential modulator of survival for cells treated with cisplatin. Preclinical and clinical studies have reported that high levels of $B R C A 1$ are associated with cisplatin chemoresistance $[18,22,23]$.

Acquired resistance to DNA adduct formation induced by platinum compounds may be also a consequence of a reduction in drug accumulation in cells due to drug inactivation and/or enhanced efflux. The glutathione $S$-transferase (GST) makes cisplatin more anionic and more readily exported from cells by the ATP-dependent glutathione $S$-conjugate export (GS-X) pump (MRP1 or MRP2). Some, but not all, translational studies have suggest that the glutathione metabolic pathway may have a role in acquired drug resistance to platinum drugs [15,24,25].

The aims of the present study were to compare the advantages and limits of a conventional chemosensitivity in vitro test with those of potentially interesting biomolecular markers in predicting response to platinum or platinum based regimens, in a series of patients with peritoneal carcinomatosis from ovarian cancer.

\section{Patients and Methods \\ Patients}

Thirty-two patients with peritoneal carcinomatosis from primary advanced (7 cases) or recurrent ( 25 cases) ovarian cancer were recruited for the in vitro chemosensitivity assay and for analysis of biomarkers potentially predictive of resistance to platinum compounds. Patients underwent surgical resection at Pierantoni Hospital in Forlì and or at Bentivoglio Hospital in Bologna. Inclusion criteria were histological confirmation of advanced or recurrent ovarian cancer and pre- or a postsurgery chemotherapy based on a platinum compound (carboplatin/ taxol or cisplatin/adriamycin or carboplatin/gemcitabine or carboplatin as monochemotherapy). It was not possible to perform the in vitro chemosensitivity test in 2 patients due to insufficient material. The remaining 30 patients all had serous tumor subtypes. Median age of patients was $60 \pm 13.3$ years (range 32-81).

Informed consent was obtained before surgical treatment and patients were required to be accessible for follow-up. The study protocol was approved by the Local Ethics Committee. In order to evaluate the correlation between gene expression or in vitro chemosensitivity and clinical response to platinum-containing treatment, patients were subdivided into responders (partial or complete clinical response and stable disease) or non-responders (progressive disease). 


\section{Treatment Evaluation}

Clinical response was evaluated by measuring circulating CA125 levels before each treatment cycle. Tumor imaging was performed every three cycles using ultrasonography or CT/MRI scans. The same clinical and instrumental evaluation was carried out every 3 months after the end of treatment.

\section{Sample Collection}

Immediately after surgical resection, tumor specimens were sampled and analyzed (under sterile conditions) by a pathologist to confirm the tumor representativity of the samples. A part of the tissue was then stored in RNAlater ${ }^{\circledR}$ Tissue Collection (Invitrogen, Carlsbad, CA) at a temperature of $+4^{\circ} \mathrm{C}$ to preserve mRNA integrity, while another part was used immediately for the chemosensitivity test.

\section{Real-Time RT-PCR Analysis}

Total RNA was extracted from fresh surgical biopsies using TRIzol ${ }^{\circledR}$ Reagent within 2 or 3 hours of surgery, in accordance with the manufacturer's instructions (Invitrogen). Reverse transcription (RT) reactions were performed in a $20-\mu$ l volume containing $800 \mathrm{ng}$ of total RNA using iScript TM cDNA Synthesis kit (Bio-Rad Laboratories, Hercules, CA) and analyzed by Real Time RT-PCR (MyiQ System, Bio-Rad) to detect the expression of the genes MGMT, BRCA1, ERCC1, GSTP1, and $X P D$. Primers for mRNA amplification were designed using Beacon Designer Software (version 4, BioRad) and sequences are listed in Table 1 . The standard reaction volume was $25 \mu \mathrm{l}$ containing $2 \mu \mathrm{l}$ of cDNA template, $1 \times$ SYBR Green Mix and $5 \mu \mathrm{M}$ of forward and reverse primers. The mixture was subjected to the following cycling conditions: $95^{\circ} \mathrm{C}$ for $1 \mathrm{~min}$ and $30 \mathrm{~s}$, followed by 40 cycles of amplification for $15 \mathrm{~s}$ at $95^{\circ} \mathrm{C}$ and $30 \mathrm{~s}$ at $59^{\circ} \mathrm{C}$ (for $X P D$ ) or $60^{\circ} \mathrm{C}$ (for $M G M T, B R C A 1, E R C C 1$, GSTP1, $\beta_{2}$-microglobulin, and hypoxanthine phosphoribosyltransferase $(H P R T))$. The amount of mRNA of each marker was normalized to the endogenous references $\beta_{2}$-microglobulin and HPRT using Gene Expression Macro Software (Version 1.1) (BioRad).
Commercial RNA control derived from a pool of normal ovarian tissue mRNA was used as calibrator.

The efficiency of amplification, which never exceeded $5 \%$ variability in the different experiments, was used to determine the relative expression of mRNA and was calculated using Gene Expression Macro Software (Version 1.1) (BioRad). The reproducibility of Real-Time PCR results was verified in triplicate, and the coefficient of variation $(\mathrm{CV})$, calculated from the three $\mathrm{C}_{\mathrm{t}}$ values, was always $<1.5 \%$.

\section{In vitro Chemosensitivity Test}

A cell suspension was obtained after 4-16 hours of enzymatic digestion of fresh tumor tissue. Cells were counted and plated at a density of 1,000,000 cells/well in 96 -well flat-bottomed microtiter plates $(100 \mu \mathrm{l}$ of cell suspension/well). Experiments were run in octuplicate. The optical density of treated and untreated cells was determined at a wavelength of $540 \mathrm{~nm}$ using a fluorescence plate reader.

Cells were exposed for 72 hours to 1,10 and $100 \mu \mathrm{M}$ of cisplatin or adriamycin; 8,80 and $800 \mu \mathrm{M}$ of carboplatin; 4, 40 and $400 \mu \mathrm{M}$ of gemcitabine; and 0.6, 6 and $60 \mu \mathrm{M}$ of taxol. Drugs were used at concentrations corresponding to peak plasma levels and were also tested at doses equivalent to one-tenth of and tenfold the peak plasma value. Drug activity was assessed by sulforhodamine B assay according to the method of Skehan et al [4]. PC3 tumor cell line, for which the dose-response curve to the anticancer agents used is known, was used as an internal control in all single experiments performed.

\section{Statistical Analysis}

The relationship between continuous (gene expression) and dichotomous variables was analyzed using a nonparametric ranking statistic (median test) [26]. Spearman's correlation coefficient $\left(\mathrm{r}_{\mathrm{s}}\right)$ was used to investigate the correlation between the mRNA expression of different genes, such as MGMT, BRCA1, ERCC1, GSTP1 and $X P D$, considered as continuous variables. Receiver operating characteristic (ROC) analysis was performed

Table 1 Oligonucleotides used for Real-Time PCR

\begin{tabular}{|c|c|c|c|}
\hline Gene name & $5^{\prime}$ to $3^{\prime}$ forward primer & $5^{\prime}$ to $3^{\prime}$ reverse primer & Annealing temperature \\
\hline$\overline{M G M T}$ & tcttcaccatcccgttttcc & attgcctctcattgctcctc & $60^{\circ} \mathrm{C}$ \\
\hline$B R C A 1$ & gctcgctgagacttcctg & gataaatccatttctttctgttcc & $60^{\circ} \mathrm{C}$ \\
\hline ERCC1 & tcagtcaacaaaacggacagtcag & tccttgggttctttcccagagc & $60^{\circ} \mathrm{C}$ \\
\hline GSTP1 & aacatgaggcgggcaag & gttgtagtcagcgaaggag & $60^{\circ} \mathrm{C}$ \\
\hline$X P D$ & aagcaggagggcgagaag & cctcatagaatcggcagtgg & $59^{\circ} \mathrm{C}$ \\
\hline HPRT & agactttgctttccttggtcagg & gtctggcttatatccaacattcg & $60^{\circ} \mathrm{C}$ \\
\hline Beta2-microglobulin & cgctactctctctttctggc & agacacatagcaattcaggaat & $60^{\circ} \mathrm{C}$ \\
\hline
\end{tabular}


for both individual markers and their combinations. We considered an algorithm that renders a single composite score using the linear predictor fitted from a binary regression model. This algorithm has been justified to be optimal under the linearity assumption $[27,28]$ that the ROC curve is maximized (i.e., best sensitivity) at every threshold value. The chi-square test was used to compare dichotomous variables.

All statistical analyses were performed with SAS Statistical Software (version 9.1, SAS Institute Inc., Cary, NC). Two-sided $\mathrm{p}$ values $<0.05$ were considered significant.

\section{Results}

The analysis of the comparison between in vitro and clinical results was performed on 30 cases with serous tumors. Fifteen patients obtained complete cytoreduction, 6 had minimal residual disease, 4 had maximum residual disease, and the remaining 5 had unresectable disease. The majority of patients (56\%) underwent carboplatin/taxol chemotherapy, 20\% received cisplatin/ adriamycin, $10 \%$ carboplatin as monochemotherapy, and $6 \%$ carboplatin/gemcitabine or carboplatin/taxol/ gemcitabine (Table 2).

\section{Gene Expression Analysis}

Of the 5 genes analyzed, MGMT and XPD expression was directly and significantly related to resistance to cisplatin-including regimens $(\mathrm{p}=0.03$ and $\mathrm{p}=0.04$, respectively) (Table 3 ). In particular, median expression

Table 2 Tumor and patient characteristics and treatment information of the case series

\begin{tabular}{|c|c|}
\hline Characteristics & No. patients \\
\hline \multicolumn{2}{|l|}{ Cancer } \\
\hline Primary & 7 \\
\hline Recurrent & 23 \\
\hline \multicolumn{2}{|l|}{ Histological type } \\
\hline Serous & 30 \\
\hline \multicolumn{2}{|l|}{ Results of cytoreduction } \\
\hline $\mathrm{CCO}$ & 15 \\
\hline $\mathrm{CC} 1$ & 6 \\
\hline CC2 & 4 \\
\hline Unresectable & 5 \\
\hline Peritoneal Cancer Index (mean and range) & $22.7(6-39)$ \\
\hline \multicolumn{2}{|l|}{ Type of treatment } \\
\hline Carboplatin/taxol & 17 \\
\hline Cisplatin/adriamicin & 6 \\
\hline Carboplatin & 3 \\
\hline Carboplatin/gemcitabine & 2 \\
\hline Carboplatin/taxol/gemcitabine & 2 \\
\hline
\end{tabular}

$\mathrm{CCO}$, complete cytoreduction; $\mathrm{CC} 1$, minimal residual disease; $\mathrm{CC}$, maximum residual disease
Table 3 Tumor gene expression to platinum-containing treatment in responders and non-responders

\begin{tabular}{lcccc}
\hline \multicolumn{5}{c}{ Median expression values (range) } \\
\hline Gene & Total patients & Responders & Non-responders & $\mathbf{p}$ \\
\hline MGMT & $\mathbf{0 . 9 0 ( 0 - 2 0 . 0 )}$ & $\mathbf{0 . 5 7}(0-2.2)$ & $\mathbf{2 . 0}(0-20.0)$ & 0.03 \\
XPD & $\mathbf{0 . 8 0 ( 0 . 0 2 7 - 1 2 . 4 )}$ & $\mathbf{0 . 5 2}(0.027-2.0)$ & $\mathbf{1 . 9}(0.11-12.4)$ & 0.04 \\
BRCA1 & $\mathbf{2 . 6 0 ( 0 - 8 7 . 4 )}$ & $\mathbf{1 . 7 3 ( 0 . 2 0 - 6 . 4 7 )}$ & $\mathbf{3 . 0}(0-87.4)$ & 0.59 \\
ERCC1 & $\mathbf{1 . 5 0 ( 0 . 4 7 - 1 5 . 0 )}$ & $\mathbf{2 . 3 0 ( 0 . 7 - 7 . 0 2 )}$ & $\mathbf{1 . 4}(0.47-15.0)$ & 0.93 \\
GSTP1 & $\mathbf{1 . 7 5 ( 0 . 1 5 - 4 5 . 0 )}$ & $\mathbf{1 . 4 7 ( 0 . 1 5 - 7 . 5 )}$ & $\mathbf{1 . 7}(0.71-45.0)$ & 0.65 \\
\hline
\end{tabular}

values of $M G M T$ and $X P D$ in tumors were about fourfold higher in non-responders than in responders.

All 5 genes were generally poorly correlated with each other; with correlation coefficients $\left(\mathrm{r}_{\mathrm{s}}\right)$ ranging from 0.577 to 0.074 . In particular, of the two genes whose expression was maximally predictive of sensitivity or resistance to clinical treatment, $X P D$ was not significantly related to ERCC1 or GSTP1, and showed borderline clinical significance with MGMT. The second, $M G M T$, was significantly related, albeit with a very poor correlation coefficient, to the other four genes (Table 4). The accuracy in predicting sensitivity or resistance to clinical treatment was analyzed for each single gene and for combinations of genes not significantly correlated with each other. Results were expressed as the area under the curve (AUC) and in terms of sensitivity, specificity and overall accuracy (Table 5). AUC values were maximum for MGMT (0.73; 95\% CI 0.53-0.94) and XPD (0.70; 95\% CI 0.48-0.91), and different gene combinations did not provide more accurate information. Only the 5 markers considered together slightly improved the AUC value (0.79; CI 0.62-0.97).

These results were paralleled by those expressed as overall accuracy: $78.5 \%$ and $75 \%$ for $M G M T$ and XPD, respectively and $75 \%$ for the 5 markers considered together. XPD expression was characterized by the highest sensitivity (89.4\%) but very low specificity (44.4\%), while MGMT showed both high sensitivity (78.9\%) and specificity $(77.8 \%)$.

\section{In Vitro Chemosensitivity Test}

In parallel, a molecular profile of chemosensitivity to all the drugs used in the clinical treatment was generated for each tumor. Patients were subdivided into responders

Table 4 Correlation between XPD or MGMT and other marker expression

\begin{tabular}{lccccccccc}
\hline & \multicolumn{2}{c}{ XPD } & \multicolumn{2}{c}{ BRCA1 } & \multicolumn{2}{c}{ ERCC1 } & \multicolumn{2}{c}{ GSTP1 } \\
\hline & $\mathbf{r}_{\mathbf{s}}$ & $\mathbf{p}$ & $\mathrm{r}_{\mathbf{s}}$ & $\mathbf{p}$ & $\mathbf{r}_{\mathbf{s}}$ & $\mathbf{p}$ & $\mathbf{r}_{\mathbf{s}}$ & $\mathbf{p}$ \\
\hline XPD & & & 0.476 & 0.007 & 0.074 & 0.696 & 0.307 & 0.099 \\
MGMT & 0.355 & 0.054 & 0.548 & 0.002 & 0.432 & 0.017 & 0.577 & 0.001 \\
\hline
\end{tabular}

$r_{s}$, correlation coefficient 
Table 5 Sensitivity and specificity of individual markers or their combination in predicting response to treatment

\begin{tabular}{lccccc}
\hline & AUC & $\begin{array}{c}\text { Cut- } \\
\text { off } \geq\end{array}$ & $\begin{array}{c}\text { Sensitivity } \\
(\%)\end{array}$ & $\begin{array}{c}\text { Specificity } \\
(\%)\end{array}$ & $\begin{array}{c}\text { Overall } \\
\text { accuracy (\%) }\end{array}$ \\
\hline MGMT & 0.73 & 0.72 & 78.9 & 77.8 & 78.5 \\
XPD & 0.70 & 0.22 & 89.4 & 44.4 & 75.0 \\
BRCA1 & 0.62 & 2.43 & 63.1 & 66.6 & 64.3 \\
ERCC1 & 0.56 & 1.37 & 73.7 & 44.4 & 64.3 \\
GSTP1 & 0.57 & 1.09 & 63.1 & 55.5 & 60.7 \\
MGMT + XPD & 0.67 & - & 63.1 & 55.5 & 60.7 \\
XPD + ERCC1 & 0.69 & - & 73.9 & 44.4 & 67.8 \\
XPD + GSTP1 & 0.69 & - & 78.9 & 44.4 & 67.8 \\
\hline Five markers & 0.79 & - & 74.0 & 77.8 & 75.0 \\
together & & & & &
\end{tabular}

AUC, area under the curve

(complete or partial clinical response and stable disease), or non-responders (progressive disease), to evaluate the correlation between in vitro chemosensitivity assay and clinical response to platinum-containing treatments (Table 6). Seventeen patients (56.6\%) were treated with carboplatin and taxol, of whom 6 had primary advanced and 11 recurrent ovarian cancer. We did not observe any significant differences in either in vitro or clinical sensitivity or resistance between primary and recurrent cancers. Considering the 2 subgroups together, concordance between in vitro results and clinical response was observed in 14 cases ( 3 in terms of sensitivity, 11 in terms of resistance). The 3 cases in whom there was no correspondence between in vitro and in vivo results were all in vitro sensitive to one drug (carboplatin or taxol); two showed clinical progression and one stable disease (Table 6). Similarly, in the subgroup of 6 patients treated with cisplatin and adriamycin, 3 were in vitro-sensitive to both drugs and showed a clinical response, while 3 were in vitro resistant to both drugs and showed disease progression. Patients treated with carboplatin ( 3 cases: 1 primary and 2 recurrent), carboplatin and gemcitabine ( 2 cases), or carboplatin, taxol and gemcitabine (2 cases) were in vitro resistant to all the drugs and all had disease progression.

\section{Comparison between the two In Vitro Approaches}

Results of the clinical response predictivity of the most relevant markers, considered singly or in combination, and of the in vitro chemosensitivity test are shown in Table 7. Significant predictivity in terms of sensitivity and resistance to the different cisplatin-based regimens was observed for MGMT expression $(75.0 \%$ and $72.5 \%$, respectively; $\mathrm{p}=0.03$ ), while high predictivity with regard to resistance $(90.9 \%)$, but very low predictivity in terms of sensitivity $(37.5 \%)(\mathrm{p}=0.06)$ were observed for $X P D$. The combined analysis of the five markers gave the highest predictivity with regard to resistance but
Table 6 Correspondence between in vitro activity and clinical efficacy in individual tumors

\begin{tabular}{|c|c|c|}
\hline & In vitro results & Clinical results \\
\hline \multirow[t]{9}{*}{ Primary } & \multicolumn{2}{|c|}{ Carboplatin/taxol } \\
\hline & $S / S$ & S \\
\hline & $R / S$ & S \\
\hline & $R / R$ & $\mathrm{R}$ \\
\hline & $R / R$ & R \\
\hline & $R / R$ & $\mathrm{R}$ \\
\hline & $R / R$ & $\mathrm{R}$ \\
\hline & \multicolumn{2}{|c|}{ Carboplatin } \\
\hline & R & $\mathrm{R}$ \\
\hline \multirow[t]{28}{*}{ Recurrent } & \multicolumn{2}{|c|}{ Carboplatin/taxol } \\
\hline & $S / S$ & S \\
\hline & $R / S$ & $\mathrm{R}$ \\
\hline & $S / S$ & s \\
\hline & $S / R$ & R \\
\hline & $R / R$ & $\mathrm{R}$ \\
\hline & $R / R$ & $\mathrm{R}$ \\
\hline & $R / R$ & $\mathrm{R}$ \\
\hline & $R / R$ & $\mathrm{R}$ \\
\hline & $R / R$ & $\mathrm{R}$ \\
\hline & $R / R$ & $\mathrm{R}$ \\
\hline & $R / R$ & R \\
\hline & \multicolumn{2}{|c|}{ Cisplatin/adriamycin } \\
\hline & $R / R$ & $\mathrm{R}$ \\
\hline & $S / S$ & S \\
\hline & $S / S$ & S \\
\hline & $S / S$ & s \\
\hline & $R / R$ & $\mathrm{R}$ \\
\hline & $R / R$ & $\mathrm{R}$ \\
\hline & \multicolumn{2}{|c|}{ Carboplatin } \\
\hline & R & $\mathrm{R}$ \\
\hline & R & $\mathrm{R}$ \\
\hline & \multicolumn{2}{|c|}{ Carboplatin/gemcitabine } \\
\hline & $R / R$ & $\mathrm{R}$ \\
\hline & $R / R$ & $\mathrm{R}$ \\
\hline & \multicolumn{2}{|c|}{ Carboplatin/taxol/gemcitabine } \\
\hline & $\mathrm{R} / \mathrm{R} / \mathrm{R}$ & $\mathrm{R}$ \\
\hline & $\mathrm{R} / \mathrm{R} / \mathrm{R}$ & $\mathrm{R}$ \\
\hline
\end{tabular}

S, sensitive; $R$, resistant

Table 7 Predictivity of clinical response by different biomarkers or in vitro chemosensitivity test

\begin{tabular}{lccc}
\hline & Sensitivity (\%) & Resistance (\%) & $\mathrm{p}$ \\
\hline Markers & & & \\
MGMT & 75.0 & 72.5 & 0.03 \\
XPD & 37.5 & 90.9 & 0.06 \\
$\quad$ Five markers & 33.3 & 100 & 0.07 \\
Chemosensitivity test & 85.7 & 91.3 & 0.0003 \\
\hline
\end{tabular}


very low predictivity in relation to sensitivity $(100 \%$ and $33.3 \%$, respectively; $\mathrm{p}=0.07$ ).

The best overall and significant predictivity was observed for the in vitro chemosensitivity test results (85.7\% sensitivity and $91.3 \%$ resistance, $\mathrm{p}=0.0003$ ). The markers were not effective in predicting resistance or sensitivity to treatment with platinum when recurrent (23) or primary (7) patients were analyzed. Conversely, the chemosensitivity test maintained a significant ability to predict response to chemotherapy in both series of patients.

\section{Discussion}

Prediction of response to drugs at preclinical level could help physicians to plan more effective tailored therapy for individuals, reduce undesirable drug toxicity and lower the cost of health care. In ovarian cancer, despite the heterogeneity of treatments available for peritoneal carcinomatosis, the majority of patients receive platinum-containing chemotherapy in either first- or secondand third-line settings. The use of the re-induction therapy in peritoneal carcinomatosis underlines the importance of studying these patients in terms of preclinical evaluation for response to platinum-containing treatments in order to avoid inactive treatments caused by acquired resistance.

There is a large body of literature highlighting a number of biomarkers as potential candidates for predicting resistance or sensitivity to treatment [11,17-22,29-33]. In the present study, we investigated the role of potentially interesting biomolecular markers and evaluated the relevance of a conventional in vitro chemosensitivity test for predicting clinical response to platinum-based regimens in patients with peritoneal carcinomatosis from ovarian cancer.

Among the markers studied, $M G M T$ and $X P D$ gene expression proved effective in predicting response to platinum-containing therapy. The MGMT gene showed good prediction with regard to both sensitivity and resistance, which, is in contrast to results obtained by Codegoni and coworkers who failed to find any relation between MGMT expression, detected by northen blot analysis, and response to platinum-based therapy in patients with primary ovarian cancer [34]. XPD expression was strongly correlated with drug resistance but weakly associated with drug sensitivity. These results are in agreement with those of Aloyz and coworkers who observed a relationship between XPD overexpression and resistance to alkylating agents in human tumor cell lines [35].

In our study the highest predictivity was observed for the in vitro chemosensitivity test used to evaluate drug activity. A strong correlation between in vitro results and clinical response was observed in 27 out of the 30 patients analyzed, with a predictivity of $85.7 \%$ in terms of sensitivity and of $91.3 \%$ in terms of resistance. The important predictive relevance of the in vitro chemosensitivity test confirms findings published by other authors on a large number of solid and hematologic tumors [9,36-40].

Evaluation of the two analytical approaches highlights the lower cost and higher accuracy, but also the longer execution time and larger amount of tumor material required by the chemosensitivity test compared to RealTime PCR determination of biomarkers, which gives rapid results using only a few nanograms of RNA.

\section{Conclusions}

In conclusion, it no longer appears ethical to treat patients with drugs to which resistance can be predicted by preclinical experimental techniques in more than $90 \%$ of cases. One solution might therefore be to use tumor material from ovarian carcinomatosis as a model for in vitro phase II studies to explore the antitumor activity of conventional and novel drugs, singly or in combination.

\section{List of abbreviations}

NER: nucleotide excision repair; ERCC1: excision repair cross-

complementation group 1 ; XPD: xeroderma pigmentosum group D; MGMT: O6 methylguanine-DNA methyltransferase; BRCA1: breast cancer gene 1; GST: glutathione S-transferase; RT: reverse transcription; ROC: receiving operating characteristic; AUC: area under the curve.

\section{Acknowledgements}

The authors would like to thank Gráinne Tierney for editing the manuscript.

\section{Author details}

${ }^{1}$ Biosciences Laboratory, Istituto Scientifico Romagnolo per lo Studio e la Cura dei Tumori (I.R.S.T.), Meldola, Italy. ${ }^{2}$ Department of Surgery and Advanced Cancer Therapies, Morgagni-Pierantoni Hospital, Forli, Italy. ${ }^{3}$ Department of Surgery, Bentivoglio Hospital, Bologna, Italy.

\section{Authors' contributions}

WZ, RS, AT and DA designed the study. CA was responsible for data acquisition and carried out the molecular genetic assays and in vitro analyses. LT performed the in vitro analyses. GMV, MF, SV and AG were responsible for patient recruitment and provided the surgical material. ES performed the statistical analyses. CA, WZ and RS drafted the manuscript. $\mathrm{DA}$ and $\mathrm{RS}$ reviewed the text for conceptual and analytic integrity. All authors read and approved the final manuscript.

\section{Competing interests}

The authors declare that they have no competing interests.

Received: 30 March 2011 Accepted: 20 June 2011

Published: 20 June 2011

\section{References}

1. Hamburger AW, Salmon SE: Primary bioassay of human tumor stem cells. Science 1977, 197:461-463.

2. Kern DH, Drogemuller CR, Kennedy MC, Hildebrand-Zanki SU, Tanigawa N, Sondak VK: Development of a miniaturized, improved nucleic acid precursor incorporation assay for chemosensitivity testing of human solid tumors. Cancer Res 1985, 45:5436-5441. 
3. Weisenthal LM, Marsden JA, Dill PL, Macaluso CK: A novel dye exclusion method for testing in vitro chemosensitivity of human tumors. Cancer Res 1983, 43:749-757.

4. Skehan P, Storeng R, Scudiero D, Monks A, McMahon J, Vistica D, Warren JT, Bokesch H, Kenney S, Boyd MR: New colorimetric cytotoxicity assay for anticancer-drug screening. J Natl Cancer Inst 1990, 82:1107-1112.

5. Carmichael J, DeGraff WG, Gazdar AF, Minna JD, Mitchell JB: Evaluation of a tetrazolium-based semiautomated colorimetric assay: assessment of chemosensitivity testing. Cancer Res 1987, 47:936-942.

6. Kangas L, Gronroos M, Nieminen AL: Bioluminescence of cellular ATP: a new method for evaluating cytotoxic agents in vitro. Med Biol 1984 62:338-343.

7. Von Hoff DD, Clark GM, Stogdill BJ, Sarosdy MF, O'Brien MT, Casper JT, Mattox DE, Page CP, Cruz AB, Sandbach JF: Prospective clinical trial of a human tumor cloning system. Cancer Res 1983, 43:1926-1931.

8. Sondak VK, Bertelsen CA, Tanigawa N, Hildebrand-Zanki SU, Morton DL, Korn EL, Kern DH: Clinical correlations with chemosensitivities measured in a rapid thymidine incorporation assay. Cancer Res 1984, 44:1725-1728.

9. Bertelsen CA, Sondak VK, Mann BD, Korn EL, Kern DH: Chemosensitivity testing of human solid tumors. A review of 1582 assays with 258 clinical correlations. Cancer 1984, 53:1240-1245.

10. Keepers YP, Pizao PE, Peters GJ, van Ark-Otte J, Winograd B, Pinedo HM: Comparison of the sulforhodamine B protein and tetrazolium (MTT) assays for in vitro chemosensitivity testing. Eur J Cancer 1991, 27:897-900.

11. Richardson A, Kaye SB: Drug resistance in ovarian cancer: the emerging importance of gene transcription and spatio-temporal regulation of resistance. Drug Resist Updat 2005, 8:311-321.

12. Bonnefoi $H$, A'Hern RP, Fisher C, Macfarlane V, Barton D, Blake P, Shepherd JH, Gore ME: Natural history of stage IV epithelial ovarian cancer. J Clin Oncol 1999, 17:767-775.

13. Funicelli L, Travaini LL, Landoni F, Trifiro' G, Bonello L, Bellomi M: Peritoneal carcinomatosis from ovarian cancer: the role of CT and [18F]FDG-PET/ CTL.,4. Abdom Imaging 2010, 35:701-707.

14. Markman M, Bundy BN, Alberts DS, Fowler JM, Clark-Pearson DL, Carson LF, Wadler S, Sickel J: Phase III trial of standard-dose intravenous cisplatin plus paclitaxel versus moderately high-dose carboplatin followed by intravenous paclitaxel and intraperitoneal cisplatin in small-volume stage III ovarian carcinoma: an intergroup study of the Gynecologic Oncology Group, Southwestern Oncology Group, and Eastern Cooperative Oncology Group. J Clin Oncol 2001, 19:1001-1007.

15. Kelland $L$ : The resurgence of platinum-based cancer chemotherapy. Nat Rev Cancer 2007, 7:573-584.

16. Shirota Y, Stoehlmacher J, Brabender J, Xiong YP, Uetake H, Danenberg KD, Groshen S, Tsao-Wei DD, Danenberg PV, Lenz HJ: ERCC1 and thymidylate synthase mRNA levels predict survival for colorectal cancer patients receiving combination oxaliplatin and fluorouracil chemotherapy. J Clin Oncol 2001, 19:4298-4304.

17. Rosell R, Taron M, Barnadas A, Scagliotti G, Sarries C, Roig B: Nucleotide excision repair pathways involved in Cisplatin resistance in non-smallcell lung cancer. Cancer Control 2003, 10:297-305.

18. Weberpals J, Garbuio K, O'Brien A, Clark-Knowles K, Doucette $S$, Antoniouk O, Goss G, Dimitroulakos J: The DNA repair proteins BRCA1 and ERCC1 as predictive markers in sporadic ovarian cancer. Int I Cancer 2009, 124:806-815.

19. Furuta T, Ueda T, Aune G, Sarasin A, Kraemer KH, Pommier Y: Transcriptioncoupled nucleotide excision repair as a determinant of cisplatin sensitivity of human cells. Cancer Res 2002, 62:4899-4902.

20. Kaina B, Christmann M, Naumann S, Roos WP: MGMT: key node in the battle against genotoxicity, carcinogenicity and apoptosis induced by alkylating agents. DNA Repair (Amst) 2007, 6:1079-1099.

21. Yarosh DB, Foote RS, Mitra S, Day RS: Repair of O6-methylguanine in DNA by demethylation is lacking in Mer- human tumor cell strains. Carcinogenesis 1983, 4:199-205.

22. Quinn JE, Carser JE, James CR, Kennedy RD, Harkin DP: BRCA1 and implications for response to chemotherapy in ovarian cancer. Gynecol Oncol 2009, 113:134-142

23. Tassone P, Di Martino MT, Ventura M, Pietragalla A, Cucinotto I, Calimeri T, Bulotta A, Neri P, Caraglia M, Tagliaferri P: Loss of BRCA1 function increases the antitumor activity of cisplatin against human breast cancer xenografts in vivo. Cancer Biol Ther 2009, 8:648-653.
24. Lewis $A D$, Hayes JD, Wolf CR: Glutathione and glutathione-dependent enzymes in ovarian adenocarcinoma cell lines derived from a patient before and after the onset of drug resistance: intrinsic differences and cell cycle effects. Carcinogenesis 1988, 9:1283-1287.

25. Yang P, Ebbert JO, Sun Z, Weinshilboum RM: Role of the glutathione metabolic pathway in lung cancer treatment and prognosis: a review. $J$ Clin Oncol 2006, 24:1761-1769.

26. Siegel S: Nonparametric statistics. London: McGraw-Hill Ltd; 1956.

27. Equchi S, Copas J: A class of logistic-type discriminant functions. Biometrika 2002, 89:1-22.

28. McIntosh MW, Pepe MS: Combining several screening tests: optimality of the risk score. Biometrics 2002, 58:657-664.

29. Naniwa J, Kigawa J, Kanamori Y, Itamochi H, Oishi T, Shimada M, Shimogai R, Kawaguchi W, Sato S, Terakawa N: Genetic diagnosis for chemosensitivity with drug-resistance genes in epithelial ovarian cancer. Int J Gynecol Cancer 2007, 17:76-82.

30. O'Toole SA, Sheppard BL, Laios A, O'Leary JJ, McGuinness EP, D'Arcy T, Bonnar J: Potential predictors of chemotherapy response in ovarian cancer-how do we define chemosensitivity? Gynecol Oncol 2007, 104:345-351.

31. Bignotti E, Tassi RA, Calza S, Ravaggi A, Romani C, Rossi E, Falchetti M, Odicino FE, Pecorelli S, Santin AD: Differential gene expression profiles between tumor biopsies and short-term primary cultures of ovarian serous carcinomas: identification of novel molecular biomarkers for early diagnosis and therapy. Gynecol Oncol 2006, 103:405-416.

32. Darcy KM, Birrer MJ: Translational research in the Gynecologic Oncology Group: evaluation of ovarian cancer markers, profiles, and novel therapies. Gynecol Oncol 2010, 117:429-439.

33. Santini D, Caraglia M, Vincenzi B, Holen I, Scarpa S, Budillon A, Tonini G: Mechanisms of disease: preclinical reports of antineoplastic synergistic action of bisphosphonates. Nat Clin Pract Oncol 2006, 3:325-338.

34. Codegoni AM, Broggini M, Pitelli MR, Pantarotto M, Torri V, Mangioni C, D'Incalci M: Expression of genes of potential importance in the response to chemotherapy and DNA repair in patients with ovarian cancer. Gynecol Oncol 1997, 65:130-137.

35. Aloyz R, Xu ZY, Bello V, Bergeron J, Han FY, Yan Y, Malapetsa A, AlaouiJamali MA, Duncan AM, Panasci L: Regulation of cisplatin resistance and homologous recombinational repair by the TFIIH subunit XPD. Cancer Res 2002, 62:5457-5462

36. Sevin BU, Peng ZL, Perras JP, Ganjei P, Penalver M, Averette HE: Application of an ATP-bioluminescence assay in human tumor chemosensitivity testing. Gynecol Oncol 1988, 31:191-204

37. Smith HS, Zoli W, Volpi A, Hiller A, Lippman M, Swain S, Mayall B, Dollbaum C, Hackett AJ, Amadori D: Preliminary correlations of clinical outcome with in vitro chemosensitivity of second passage human breast cancer cells. Cancer Res 1990, 50:2943-2948.

38. Nagai $N$, Minamikawa K, Mukai K, Hirata E, Komatsu M, Kobayashi $\mathrm{H}$ : Predicting the chemosensitivity of ovarian and uterine cancers with the collagen gel droplet culture drug-sensitivity test. Anticancer Drugs 2005, 16:525-531.

39. Kim HA, Yom CK, Moon Bl, Choe KJ, Sung SH, Han WS, Choi HY, Kim HK, Park HK, Choi SH, et al: The use of an in vitro adenosine triphosphatebased chemotherapy response assay to predict chemotherapeutic response in breast cancer. Breast 2008, 17:19-26.

40. Cree IA, Kurbacher CM, Lamont A, Hindley AC, Love S: A prospective randomized controlled trial of tumour chemosensitivity assay directed chemotherapy versus physician's choice in patients with recurrent platinum-resistant ovarian cancer. Anticancer Drugs 2007, 18:1093-1101.

doi:10.1186/1479-5876-9-94

Cite this article as: Arienti et al:: Peritoneal carcinomatosis from ovarian cancer: chemosensitivity test and tissue markers as predictors of response to chemotherapy. Journal of Translational Medicine 2011 9:94. 